\title{
Philosophiques
}

\section{Collaborateurs et collaboratrices}

Volume 21, numéro 2, automne 1994

Les femmes et la société nouvelle

URI : https://id.erudit.org/iderudit/027292ar

DOI : https://doi.org/10.7202/027292ar

Aller au sommaire du numéro

Éditeur(s)

Société de philosophie du Québec

ISSN

0316-2923 (imprimé)

1492-1391 (numérique)

Découvrir la revue

Citer ce document

(1994). Collaborateurs et collaboratrices. Philosophiques, 21(2), 547-548.

https://doi.org/10.7202/027292ar d'utilisation que vous pouvez consulter en ligne.

https://apropos.erudit.org/fr/usagers/politique-dutilisation/ 


\section{COLLABORAIEURS ET COLLABORATRICES}

Louky BERSIANIK. Écrivaine, auteure de plusieurs ouvrages importants d'inspiration féministe, dont L'Euguélionne, Le pique-nique sur l'Acropole, Les agénésies du vieux monde et La main tranchante du symbole.

Guy BOUCHARD. Professeur à la Faculté de philosophie de l'Université Laval, et écrivain. A publié, entre autres, Le procès de la métaphore, Les gélules utopiques (roman), Orwell et « 1984» : trois approches (en coll.), Femmes et pouvoir dans la « cité philosophique »: Relire «L'Utopie » de Thomas More.

Nicole BROSSARD. Écrivaine, fondatrice de L'intégrale éditrice. Parmi ses nombreux ouvrages, on peut signaler : L'amer ou le chapitre effrité, Le sens apparent, Picture Theory, Journal Intime et Le désert mauve.

Yvan CLOUTIER. Professeur au Collège de Sherbrooke, ainsi qu'aux départements de philosophie et de sciences humaines de l'Université de Sherbrooke. Spécialiste de Sartre, à qui il a consacré plusieurs articles.

Jean-Guy CôTÉ. Étudiant au doctorat en philosophie (Université Laval) et stagiaire de formation en psychologie clinique. Auteur d'un article sur Hannah Arendt: «Pouvoir de la métaphore ou métaphore du pouvoir? »

Ariane Michelle DJOssoU. Étudiante au doctorat en philosophie (Université Laval). A publié quelques articles, dont « Les femmes et le pouvoir politique ».

Carolle GAGNON. Professeure au Département de philosophie de l'Université de Moncton. Auteure de plusieurs articles en muséologie, en histoire de l'art et en esthétique, ainsi que d'un ouvrage en collaboration intitulé Marcel Barbeau. Regard en fugue.

John GALLUP. Professeur à la Faculté de philosophie de l'Université Laval. Spécialiste d'Aristote et des problèmes du langage. Son texte le plus récent: « Le pronom comme réitération syntaxique du nom ».

Diane LAMOUREUX. Professeure au Département de science politique de l'Université Laval. Auteure de multiples articles et volumes, dont Fragments et collages, essai sur le féminisme québécois des années 70. 
Michel LAVOIE. Étudiant au doctorat en philosophie (Université Laval). A publié « Premier fondement du pouvoir totalitaire: l'opposition Femme/Homme dans 1984 de Georges Orwell ».

Sylvie MASSÉ. Étudiante au doctorat en littérature québécoise. Son mémoire de maîtrise, récipiendaire du prix Grégory-McGill, a été publié. Elle a aussi signé deux articles d'intérêt féministe.

Marie-Josée Morin. Étudiante à la maîtrise en philosophie (Université Laval). A publié deux nouvelles et un article : « From the Legend of Biel : les nouvelles techniques de reproduction humaine au service de l'autonomie individuelle ».

Steven MORIN. Étudiant en littérature à l'Université Laval. Prépare une maîtrise sur la relation mère-fille dans l'oeuvre de Marguerite Duras.

Daphne PATAI Professeure au Département d'espagnol et de portugais, ainsi qu'au Département d'études sur les femmes de l'Université du Massachusetts. Spécialiste des utopies féministes. Auteure, entre autres, de The Orwell Mystique: A Study in Male Ideology, et de Women's Words: The Feminist Practice of Oral History (en coll.).

Esther ROCHON. Écrivaine. Auteure de plusieurs romans, dont En hommage aux araignées, L'épuisement du soleil et L'espace du diamant. A reçu à trois reprises le grand prix de la science-fiction et du fantastique québécois.

Marie-Andrée ROY. Professeure à l'Université du Québec à Montréal. Spécialiste des rapports entre les femmes et la religion, elle a publié dans des revues comme Réseaux, Recherches féministes et Cahiers internationaux du symbolisme.

Francine SAILLANT. Professeure à l'École des sciences infirmières de l'Université Laval. Auteure de plusieurs articles, dont « Les soins en péril, entre la nécessité et l'exclusion ».

Chantal THéRY. Professeure au Département des littératures de l'Université Laval. A publié plusieurs articles, dont « Les écrivaines de la Nouvelle-France : entre le mal du pays et prendre pays ».

Hélène TURCOTTE. Etudiante au doctorat en littérature québécoise (Université Laval). Sa thèse porte sur les premières journalistes et écrivaines canadiennes-françaises. A publié quelques nouvelles.

Raynald VALOIS. Professeur à la Faculté de philosophie de l'Université Laval. Ses publications les plus récentes ont trait à la pensée de Carl Gustav Jung.

Elisabeth VONARBURG. Ecrivaine. A publié plusieurs nouvelles, recueils de nouvelles et romans, dont L'oeil de la nuit, Le silence de la cité, Janus, Ailleurs et au Japon et Chroniques du pays des mères. 